\title{
ON THE DESIGN OF COATING SYSTEM USING NANOMECHANICAL EXPERIMENTS
}

\author{
David Mercier ${ }^{a *}$, Claes FredriKsson $^{b}$ \\ a ANSYS Granta - Education Division, Tour Part-Dieu 129 Rue Servient, Lyon, 69003 France \\ ${ }^{b}$ ANSYS Granta - Education Division, 62 Clifton Road, Cambridge, CB1 7EG United Kingdom \\ * corresponding author: david.mercier@ansys.com
}

\begin{abstract}
The aim of this paper is to identify performance indices for the design of coating systems, using results from nanomechanical tests. The use of nanoindentation, nanoscratch and pin-on-disk experiments applied to coatings for mechanical and tribological property estimation is presented. Then, multiple performance indices, based on experimental and numerical results found in the litterature, are listed in order to help the material selection and optimization of durability and performance of coatings.
\end{abstract}

KEYWORDS: Coating, fracture, material selection, nanoindentation, performance index, scratch.

\section{INTRODUCTION}

The use of coatings to improve surface properties of components is constantly increasing [1, 2] and the significance of material selection in coating systems design is well recognized [3-5]. The definition of the material combined with the coating structure is a key step in the design process, particularly in the field of surface protection from damage in mechanical systems [6]. In this context, the multiscale mechanical stability of coatings on substrates can be characterized using nanomechanical experiments [7-12]. The knowledge of the mechanical and tribological behavior of the coating, the coating-substrate interface and the substrate, enables the construction of selection maps (material property or failure mechanism) [3, 13, 14]. Ashby's methodology with specific performance indices, as implemented in the GRANTA Selector software [8, 15 17], can be employed for this purpose, see Figure 1 .

Selection maps help engineer coatings by linking coating performance with its structure, material property and the coating process (elaboration and surface treatment).

A summary of mechanical and tribological properties extracted from experimental results, based on nanoindentation, nanoscratch and pin-on-disk techniques, is given in Table 1 below.

These experiments are often used to promote the analysis of load $(F)$ or contact stiffness $(S)$ vs. vertical displacement $(h)$ or horizontal displacement $(d)$ curves, which can be coupled with corresponding microscopic observations of residual indents or grooves. Schemes of residual imprints are given for each experiment with the description of geometrical parameters used in the equations. The indices $n, t$, ind, crit, max, $c, s$, int and $R$ in Equations 1 to 13 refer, respectively, to the normal and tangential axis to the coating surface, the indenter properties, the critical event (crack formation, dislocation nucleation, etc.) associated with a pop-in or a jump on the load-displacement curve, to a maximum parameter value, the coating, the substrate, the coating-substrate interface and to the residual value. $E$ ' in Equation 1 represents the reduced elastic modulus with both indenter and material elastic contributions. Knowing Poisson's ratio, $\nu$, of the indented material and elastic properties of the indenter, it is possible to estimate the elastic modulus of the tested material using Equation 2 Alpha $(\alpha)$ in Equation 5 is an empirical constant, usually taken to be about 0.016 , based on a fit to experimental data. Finally, the coating thickness in Equations 7 to 9 is denoted $t$ and the residual stress of the material used in Equation 9, is referred to as $\sigma_{\mathrm{R}}$. Based on the combination of these materials properties, performance indices (PIs) can be established to characterize the performance of a material in a given application. A non-exhaustive list obtained from the literature is proposed, see Table 2, below.

Within Table $2 F_{\text {crit }}$ in Equation 24 corresponds to the critical load estimated during a scratch test, when the penetrator is touching the substrate surface and the coating no longer plays its protective role. These criteria, defined as a function of the mechanical surface solicitation, tend to describe a specific resistance of the coating system. Based on the PIs in Table 2 some examples of material property maps and failure mechanism maps have been created for different case studies. On one hand, property maps are usually quantitative and directly plotted using experimental results given in each reference papers, and on the other hand failure mechanisms maps are qualitative and based on a correlation between the observed failure mechanisms trend and the level of different properties or PIs. These results are presented and discussed in section 2 below. 


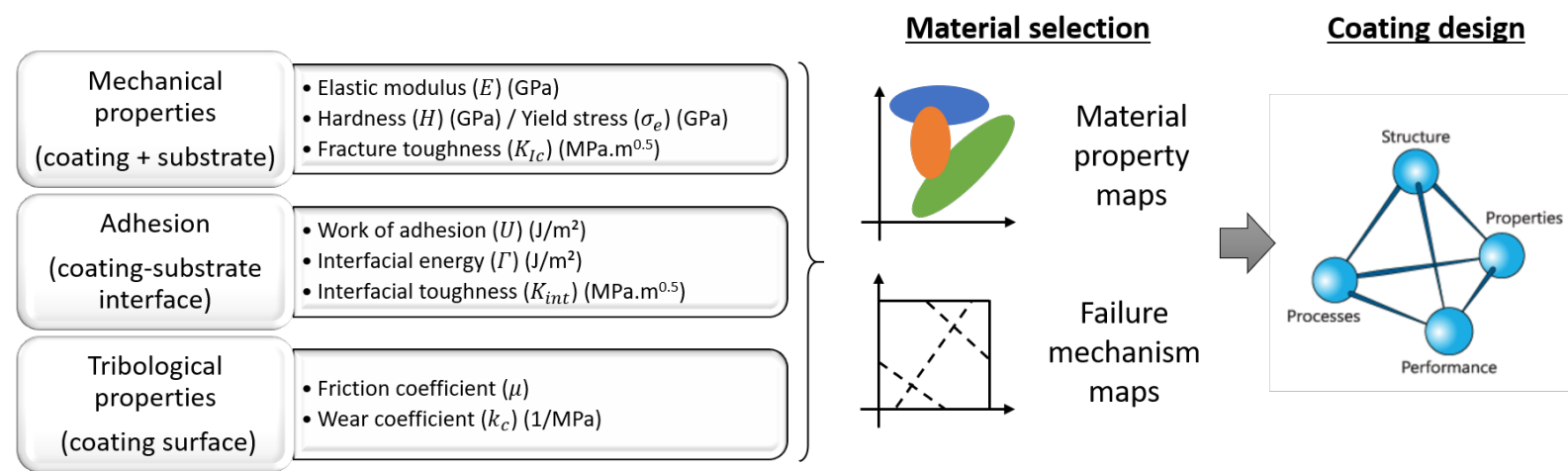

FiguRE 1. Properties required for selection maps creation to support coating systems design.

\section{Results AND DISCUSSION}

\subsection{The CASE OF HOMOGENEOUS COATINGS}

The first example of material coating selection is about substrate surface durability and improvement by elaborating sol-gel coatings on glass and steel samples 22 . For these sol-gel coatings, the effective elastic moduli as well as the hardness values, along the indentation depth, were estimated using Equations 1 to 3. The effect of substrate, of the presence of nanoparticles (NPs) and of annealing at higher temperature were studied. Then, the mechanical failure modes of solgel coatings were investigated using both Berkovich nanoindentation and nanoscratch technique. Microscopic observations of residual imprints and residual grooves show that both exhibit chipping in the case of thick coatings, especially on glass substrate, and no dramatic failure for thin coatings applied on both substrates. It is found that the mechanical properties of the sol-gel and the mechanical stability of the coatings on substrates are influenced dramatically by the presence of nanoparticles and the thermal treatment. The interfacial fracture toughness of sol-gel coatings on substrate was estimated using Equations 9 to 11. Material property and failure mechanism maps based on experimental results were then created using performance indices from Table 2, These can subsequently guide the sol gel coating selection, see Figure 5. It appears that annealed sol-gel coating containing NPs are the best candidates in this case, offering mechanical protection with good adhesion.

\subsection{The CASE OF COMPosite COATINGS}

In the second example, a Particle Reinforced Metal Matrix Composites (PRMCC) coating, deposited on a steel substrate is studied for its protection against corrosion and for its good wear resistance. These are two properties of primary importance for mechanical applications [9, 23. A thick nickel coating containing micrometric Silicon Carbide ( $\mathrm{SiC}$ ) particles was electro-deposited on a steel substrate from a suspension of $\mathrm{SiC}$ in a Watts-type Ni-plating bath. The texture and microstructure of the coating were examined using electron backscatter diffraction combined with energy-dispersive spectroscopy for phase differentiation. The interfacial strength between the Ni matrix and the SiC particles was investigated by nanoscratch experiments. Grid nanoindentation technique coupled with an image correlation-based targeted indentation analysis and a statistical data treatment were employed. The mechanical properties of the composite were quantified, and the mechanical properties of each phase were extracted, using Equations 1 to 3 . Finally, empirically knowing the material property of the PRMMC coating (light blue bubble on Figure 6 a) and of the raw reference materials ( $\mathrm{Ni}$ and $\mathrm{SiC}$ data from 15), it is possible to create an Ashby map and a failure mechanism map for this example (Figure 6). The green, dark blue and small orange dots on the Ashby map are obtained using Voigt, Reuss and Voigt-Reuss laws of mixture, with reference material property. The conclusion of this example is that PRMMC have very interesting mechanical properties arising from the combination of a relatively ductile matrix (less fracture) with harder reinforcing particles (less wear).

\subsection{The CASE OF MUltilayer COATINGS}

The third case study is based on the development of multilayer structures with diamond-like carbon (DLC) coating on the top surface to protect steel substrates from wear [8]. In this framework, graded compositions based on $\mathrm{Cr} / \mathrm{CrN} /(\mathrm{Cr}, \mathrm{N})-\mathrm{DLC}$ and $\mathrm{Cr} / \mathrm{Cr}$-DLC coatings were used to progressively increase the coating hardness and to improve the adhesion of the DLC layer. The mechanical and tribological properties of these multilayer structures were obtained by nanoindentation, nanoscratch, and ball-on-disk tribometer. Using performance indices based on a mix of adhesion, mechanical and tribological properties, material property and failure mechanism maps were proposed (Figure 7). Based on these results, the combination of a thick DLC layer with a Cr base is a promising solution for mechanical and wear protection, in the case of steel substrates. 


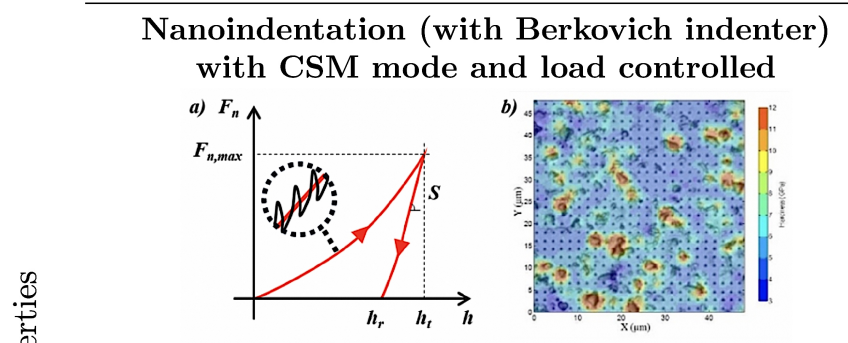

Figure 2. a) Load-Displacement curve and b) example of hardness indentation map

\section{Nanoindentation (with sharp pyramidal} indenter) load controlled
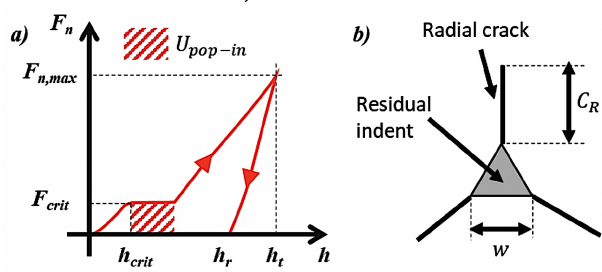

FiguRE 3. a) Load-Displacement curve and b) scheme of residual indent with radial cracking.

\section{Nanoindentation or Nanoscratch}

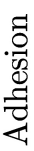
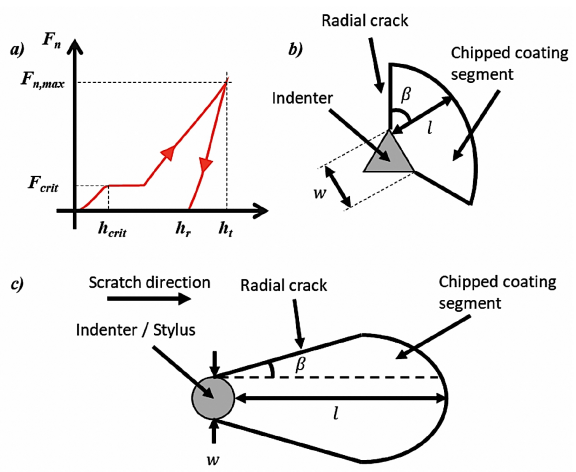

Figure 4. a) Load-Displacement curve and b) and c) schemes of residual imprints.

\section{Nanoscratch or Pin-on-disk tribometry}
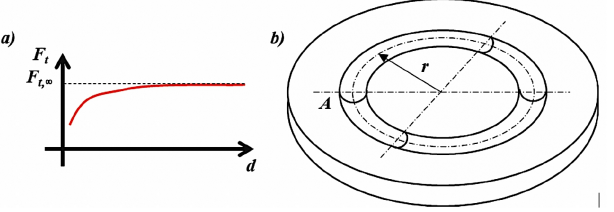

FIGURE 5. a) Tangential load-distance curve and b) scheme of residual groove (pin-on-disk).

$$
\begin{gathered}
E^{\prime}=\frac{S}{2 \cdot 1.034} \sqrt{\frac{\pi}{f\left(F_{\mathrm{n}}, h\right)}} \\
E=\left(1-\nu^{2}\right)\left(\frac{1}{E^{\prime}}-\frac{1-\nu_{\text {ind }}^{2}}{E_{\text {ind }}}\right)^{-1} \\
H=\frac{F_{\mathrm{n}, \max }}{f\left(F_{\mathrm{n}}, h\right)} \\
\sigma_{e}=\frac{H}{2.8} \\
K_{\mathrm{Ic}}=\alpha\left(\frac{E}{H}\right)^{0.5}\left(\frac{F_{\text {crit }}}{C_{\mathrm{R}}^{1.5}}\right) \\
K_{\mathrm{Ic}}=\left[\left(\frac{H_{\mathrm{Ic}}}{\frac{H^{3} \cdot F_{\text {crit }}}{21.7 \times 10^{3}}} \frac{E}{\left(1-\nu^{2}\right) 2 \pi C_{\mathrm{R}}}\right)\left(\frac{U_{\text {pop }- \text { in }}}{t}\right)\right]^{0.5}
\end{gathered}
$$

$$
K_{\mathrm{int}}=\sqrt{\Gamma E_{\mathrm{int}}}
$$

TABLE 1. Summary of nanomechanical experiments and expected results for mechanical properties, adhesion and tribological property calculations. CSM is for continuous stiffness measurement. 


\begin{tabular}{|c|c|c|c|c|}
\hline $\begin{array}{l}\text { Mechanical surface } \\
\text { solicitation }\end{array}$ & $\begin{array}{l}\text { Criterion } \\
\text { definition }\end{array}$ & PI definition & Eq. & Ref. \\
\hline \multirow{2}{*}{ Blunt indentation } & $\begin{array}{l}\text { Yielding } \\
\text { resistance }\end{array}$ & $\frac{H^{3}}{E^{2}}$ & (14) & [15] \\
\hline & $\begin{array}{l}\text { Cracking } \\
\text { resistance }\end{array}$ & $\frac{K_{I c}^{2}-\left(1-\nu^{2}\right)}{E}$ & (15) & [15] \\
\hline \multirow{2}{*}{ Blunt scratch } & $\begin{array}{l}\text { Yielding } \\
\text { resistance }\end{array}$ & $\frac{H^{3}}{E^{2}}$ & (16) & [15] \\
\hline & $\begin{array}{l}\text { Cracking } \\
\text { resistance }\end{array}$ & $\frac{K_{I c}^{3}}{E^{2}(1-2 \nu)^{3}}$ & (17) & [15] \\
\hline \multirow{2}{*}{ Sharp indentation } & $\begin{array}{l}\text { Yielding } \\
\text { resistance }\end{array}$ & $H$ & (18) & $15]$ \\
\hline & $\begin{array}{l}\text { Cracking } \\
\text { resistance }\end{array}$ & $\frac{K_{I c}^{4}}{H^{3}}$ & (19) & 15 \\
\hline \multirow{2}{*}{$\begin{array}{l}\text { Indentation and scratch } \\
\text { "Hard-film-on-soft-substrate" }\end{array}$} & $\begin{array}{l}\text { Yielding } \\
\text { resistance }\end{array}$ & $\frac{E_{c}^{\prime 1 / 3}}{E_{s}^{\prime 1 / 3}} \sqrt{\sigma_{e, s}}$ & (20) & [16] \\
\hline & $\begin{array}{l}\text { Cracking } \\
\text { resistance }\end{array}$ & $K_{I c}^{2 / 3}$ & (21) & [16] \\
\hline Sliding contact & $\begin{array}{l}\text { Wear resistance } \\
\text { "elastic strain to failure" }\end{array}$ & $\frac{H}{E}$ & $(22)$ & [11, 18, \\
\hline Indentation or scratch & $\begin{array}{l}\text { Chipping } \\
\text { resistance }\end{array}$ & $K_{i n t}, \Gamma$ or $U$ & (23) & [19] \\
\hline Sliding contact & Scratch resistance & $\frac{F_{\text {crit }}}{\mu}$ & (24) & 8 \\
\hline Sliding contact & Wear resistance & $k$ & $(25)$ & [20, 21] \\
\hline
\end{tabular}

TABlE 2. Non-exhaustive list of performance indices for coating system design.

a)

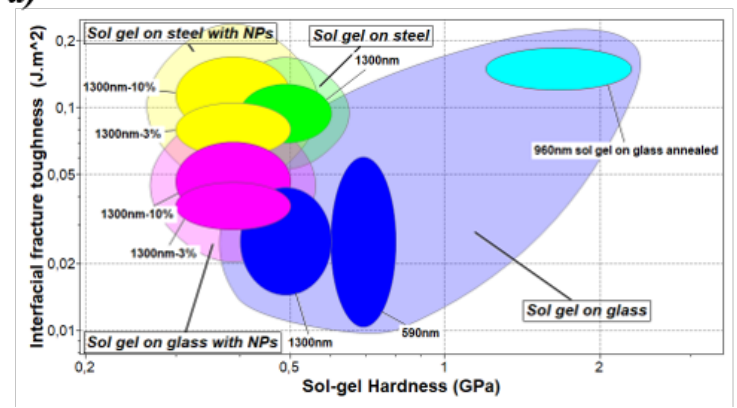

b)

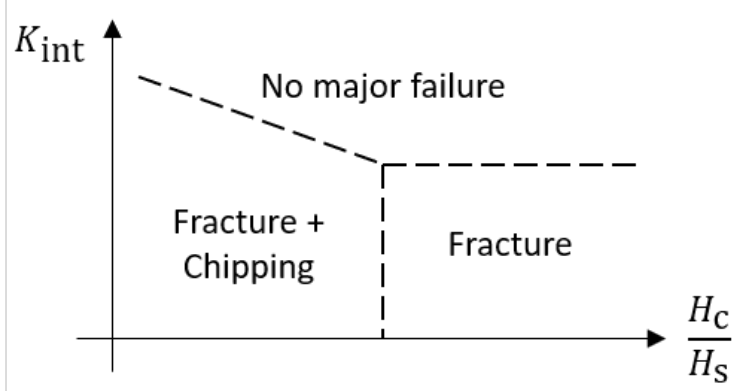

FIgURE 5. a) Material property map and b) failure mechanism map for sol gel coating.

\section{Conclusions}

This paper presents mechanical and tribological design considerations of different coating systems and investigates nanomechanical techniques and performance indices bases methods for their assessment. Through different case studies, the use of nanoindentation, nanoscratch and pin-on-disk techniques are presented for the characterization of mechanical sta- bility for several coated substrates. The material selection is based on a combination of experimental results with material property and failure mechanism maps. Finally, the knowledge of material (substrate and coating), of the interface and of the surface coating property, coupled with failure mechanism analysis is a keystone in the selection process for coatings design application. 


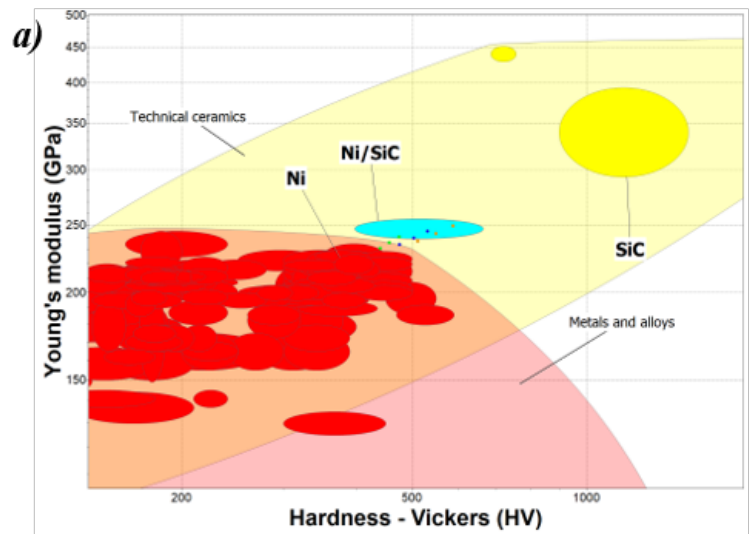

b)

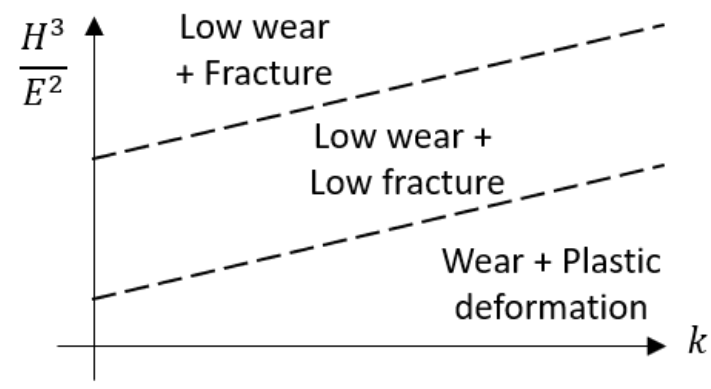

FiguRE 6. a) Material property map and b) failure mechanism map for PRMMC coating selection.
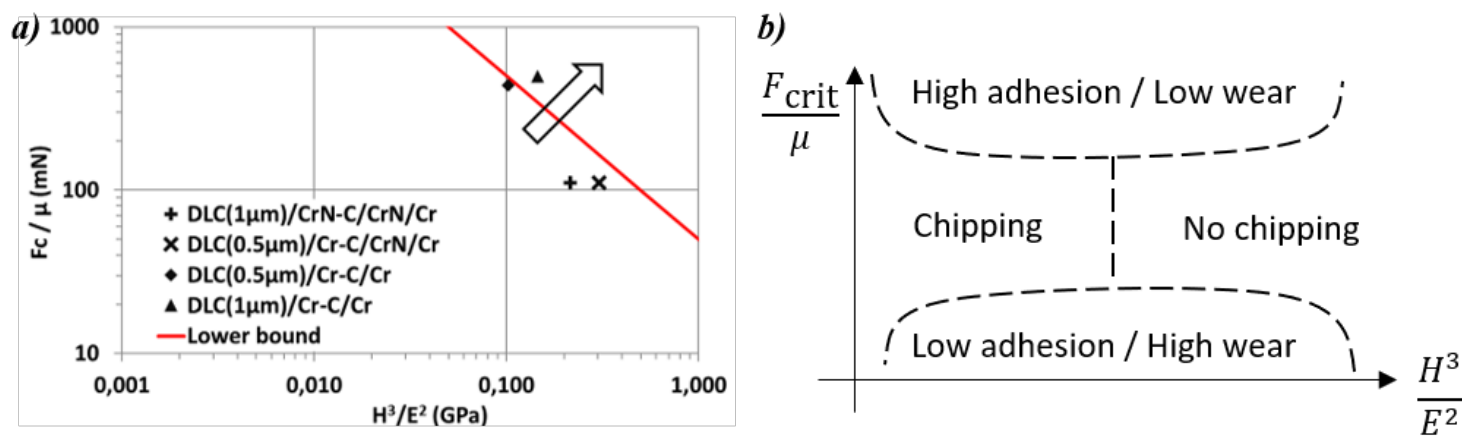

FiguRE 7. a) Material property map and b) failure mechanism map for DLC multilayer coating.

\section{ACKNOWLEDGEMENTS}

This work was partially performed under the support of the BEWARE FELLOWSHIPS programs co-financed by the COFUND program of the European Union (FP7 Marie Curie Actions - INDMAT nº: 1510385).

\section{REFERENCES}

[1] L. Li, Q. Yang. Advanced Coating Materials. John Wiley \& Sons, 2018. DOI:10.1002/9781119407652

[2] B. Fotovvati, N. Namdari, A. Dehghanghadikolaei. On coating techniques for surface protection: A review $\mathbf{3}$, 2019. DOI:10.3390/jmmp3010028

[3] M. Ashby. Materials selection in mechanical design fifth edition 2017.

[4] M. Ashby. Multi-objective optimization in material design and selection. Acta Materialia 48(1):359 - 369, 2000. DOI:10.1016/S1359-6454(99)00304-3

[5] H. Holleck. Designing advanced coatings for wear protection. Surface Engineering 7(2):137-144, 1991. DOI:10.1179/sur.1991.7.2.137.

[6] D. Luo. Selection of Coatings for Tribological Applications: Choix Des Revêtements Pour Applications Tribologiques. 2009.

[7] D. Mercier, V. Mandrillon, G. Parry, et al. Investigation of the fracture of very thin amorphous alumina film during spherical nanoindentation. Thin Solid Films 638:34-47, 2017. DOI:10.1016/j.tsf.2017.07.040
[8] F.-D. Duminica, R. Belchi, L. Libralesso, D. Mercier. Investigation of $\mathrm{Cr}(\mathrm{N}) / \mathrm{DLC}$ multilayer coatings elaborated by PVD for high wear resistance and low friction applications. Surface and Coatings Technology 337:396 - 403, 2018. DOI:10.1016/j.surfcoat.2018.01.052

[9] D. Mercier, J.-F. Vanhumbeeck, M. Caruso, et al. Microstructural and mechanical characterisation of electroplated nickel matrix composite coatings. Surface Engineering 35(2):177-188, 2019. DOI: $10.1080 / 02670844.2018 .1433270$

[10] K. Holmberg, A. Matthews. Coatings tribology: properties, mechanisms, techniques and applications in surface engineering. Elsevier, 2009.

[11] A. Matthews, S. Franklin, K. Holmberg. Tribological coatings: contact mechanisms and selection. Journal of Physics D: Applied Physics 40(18):5463-5475, 2007. DOI:10.1088/0022-3727/40/18/s07

[12] R. J. Bayer. Mechanical Wear Fundamentals and Testing, revised and expanded. CRC Press, 2004.

[13] F. Zok, A. Miserez. Property maps for abrasion resistance of materials. Acta Materialia 55(18):6365 6371, 2007. DOI:10.1016/j.actamat.2007.07.042.

[14] S. Bull. Failure mode maps in the thin film scratch adhesion test. Tribology International 30(7):491 - 498, 1997. DOI:10.1016/S0301-679X(97)00012-1

[15] Granta design, CES selector, 2019.

[16] A. Favache, A. Daniel, A. Teillet, T. Pardoen. Performance indices and selection of thin hard coatings on soft substrates for indentation and scratch resistance. 
Materials \& Design 176:107827, 2019. DOI:10.1016/j.matdes.2019.107827.

[17] J. Ast, M. Ghidelli, K. Durst, et al. A review of experimental approaches to fracture toughness evaluation at the micro-scale. Materials 85 Design 173:107762, 2019. DOI:10.1016/j.matdes.2019.107762

[18] A. Leyland, A. Matthews. On the significance of the $\mathrm{h} / \mathrm{e}$ ratio in wear control: a nanocomposite coating approach to optimised tribological behaviour. Wear 246(1): 1 - 11, 2000.

DOI:10.1016/S0043-1648(00)00488-9

[19] J. Malzbender, J. den Toonder, A. Balkenende, G. de With. Measuring mechanical properties of coatings: a methodology applied to nano-particle-filled sol-gel coatings on glass. Materials Science and Engineering: R: Reports 36(2):47 - 103, 2002. DOI:10.1016/S0927-796X(01)00040-7
[20] W. M. Silva, P. S. Souza, J. R. Carneiro. Methods of data analysis for the ball cratering test on TiN and DLC coated steel. Materials Research 19:9 - 17, 2016.

[21] S. Montgomery, D. Kennedy, N. O'Dowd. Analysis of wear models for advanced coated materials 2009.

[22] D. Mercier, A. Nicolay, A. Boudiba, et al. Mechanical properties and decohesion of sol-gel coatings on metallic and glass substrates. Journal of Sol-Gel Science and Technology 2019. DOI:10.1007/s10971-019-05196-9

[23] D. Mercier, J.-F. Vanhumbeeck, M. Caruso, $\mathrm{X}$. Vanden Eynde. Caracterisation mecanique par nanoindentation d'un revetement composite a matrice nickel electrodepose. Materiaux \& Techniques 105:106, 2017. DOI:10.1051/mattech/2017014 